\title{
Archives use of social media \\ to develop connections \\ with family historians
}

by

\section{Julie Paterson}

Submitted to the School of Information Management,

Victoria University of Wellington

in partial fulfilment of the requirements for the degree of

Master of Information Studies

April 2011 


\section{Table of Contents}

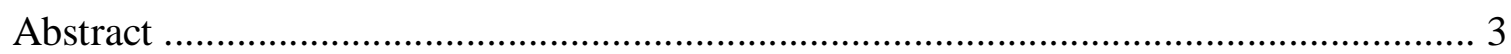

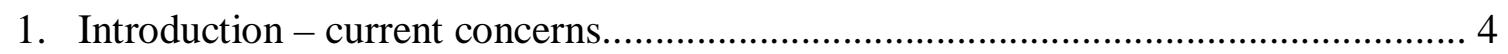

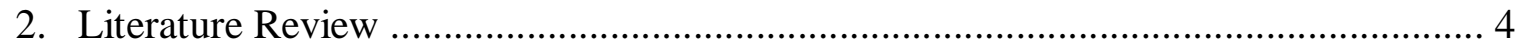

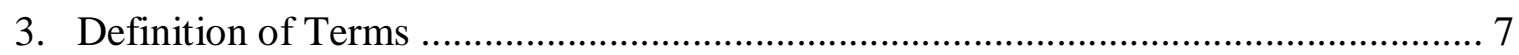

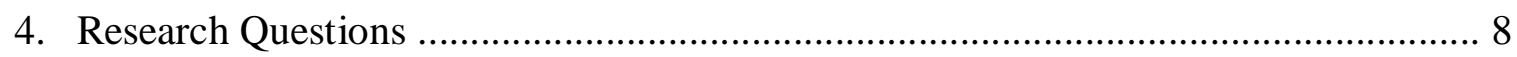

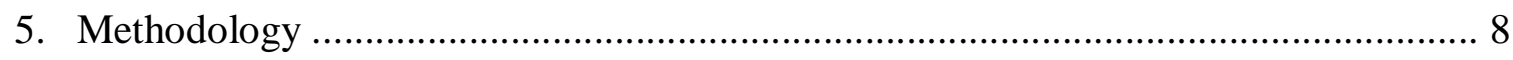

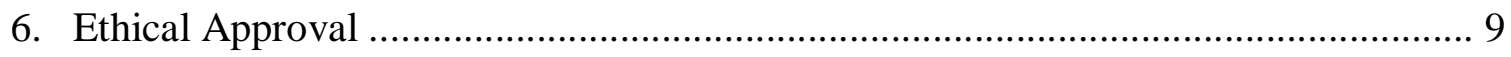

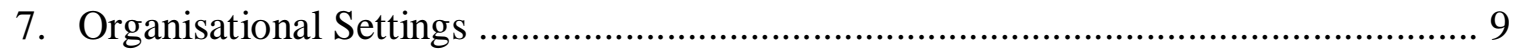

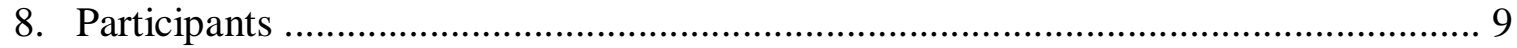

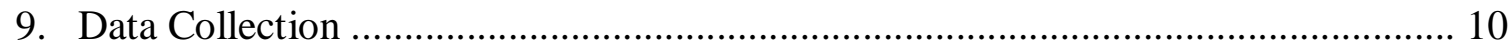

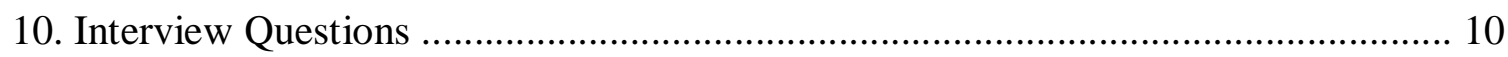

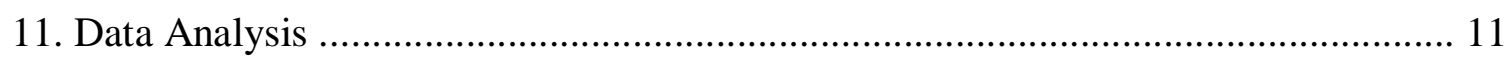

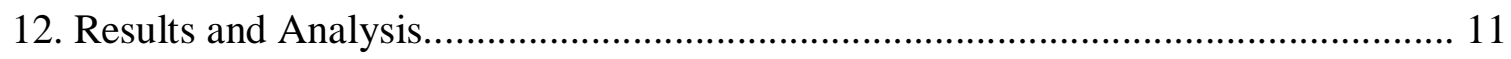

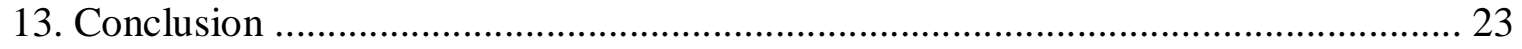

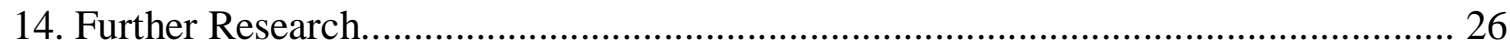

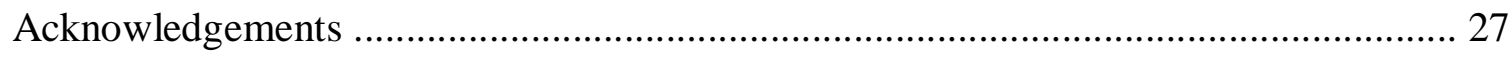

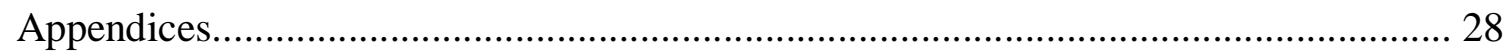

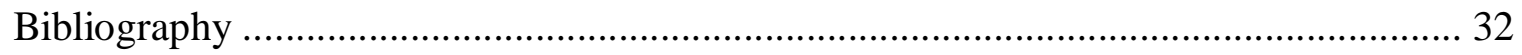




\begin{abstract}
The purpose of this paper is to report the results of a research project designed to investigate how social media is being used by archives to develop connections with family historians.

This research used qualitative methodology and utilised Skype and Instant Messaging to conduct semi-structured interviews with participants from six archives. The research uses Rogers’ Diffusion of Innovation theory as a framework.

The research found the interviewees were using social media in various combinations to serve different purposes. In the majority of cases these tools were being used to achieve maximum access to the wider online community. The study highlights issues and concerns discussed by participants when using social media. There were limited examples of social media use to make connections with family historians during the study. Nonetheless this paper provides three detailed instances of its use to illustrate how archives can make these connections.
\end{abstract}

Keywords - Archives, Social Media, Family Historians 


\section{Introduction: current concerns}

Family historians are frequent users of archival materials in both archives and libraries as these facilities provide a valuable starting point to family stories. They come in the hope of uncovering and verifying family information, wanting to know what to use and how to use it. As a user group they have a diverse range of research experience, thereby creating a challenge for archive and library administration.

The internet has revolutionised the written record search for family historians. As more historical records are made available online it is important that archival organisations promote their presence and services to users. With the advent of social media, archives must meet the challenge of utilising new tools to supplement and improve services, ultimately with the intention of building stronger connections with the online community.

As online access improves there is a corresponding need to develop dynamic, interactive and responsive on-line retrieval systems (Anderson, 2004). Recent studies into the use of social media within archives predominantly focus on the introduction of new concepts, taking into account both implementation and content issues, but research concerning how these tools are making meaningful connections with users remains limited.

\section{Literature Review}

New Zealanders are increasing their participation in social media with content sharing the most popular social media activity: $81 \%$ sent or shared a photo, $75 \%$ posted photos online, and $73 \%$ sent or shared a link.

Of regular online activities, reading wikis is up 26\%, creating social network profiles is up $16 \%$, updating social network profiles is up 17\%, looking at others' social network profiles is up $16 \%$

(Nielson’s 2010 Social Media Report)

The literature on social media use by archives discusses predominately conceptual issues and ideals. Perhaps because it is a relatively new area of research with many authors keen to share success stories there is little evidence of critical analysis. 
Social media are web based technologies that can take many different forms. They allow relatively anyone to publish or access information and provide a platform to communicate and collaborate more easily online. Using the internet to blend social interaction, usergenerated content and mobile technologies together is encouraging fast uptake by users. Archives are utilising these free and accessible tools to promote collections and establish an interactive online presence. Weblogs, wikis, Flickr, Facebook, Twitter, podcasts, video and social bookmarking are all being used by archives to engage collaboratively and more openly with users. Sutherland (2010) comments on the outcome of using Flickr to share heritage photographs online: "We have had an increased awareness of our existing image collections, and an increase in contributions of objects, both physical and to loan, along with the enrichment of information supplied by the community and the conversations that occur around the images in such a social space.” (p11) Such remarks help explain why archives are experimenting with social media; however research remains limited as to what conversations are occurring with these technologies.

The public profile of archives has increased through media programmes such as "Who Do You Think You Are?” which in turn boost both the profile of archival records and the pursuit of family history. Barratt (2009) suggests this has led to a new genre of historical research, "personal heritage - which combines the history of one's ancestors with the story of where they lived, worked and died, interlaced with the history of events in the local community.” (p10)

A recent research study of the use of archives by family historians found that in Europe and North America this group can now account for 50\% to 90\% of all users (Tucker, 2006). This has led to challenges for archivists and changes in user expectations. As Oliver (2010) states "the users of government archives are enormously diverse, and because of that diversity they bring very different sets of skills and expertise to their interactions with the archives, which of course impacts on staff." She acknowledges that "the transition from focusing on the elite to a much more multi-faceted user profile certainly has not been easy or painless.” However online family history research now offers new opportunities to archives and is "the chance to open our doors wider” (Tucker, p155).

Family history has been neglected worldwide by archival studies and Tucker observes that family historians form a community of "critical importance” (p130) to archives with the web becoming the tool to serve these researchers. In fact, family historians may now never set 
foot in a physical facility and yet "search and use digital documents, images, audio files, and videos from anywhere in the world." (Smith, p4) Archives should learn to "promote learning by others through our expertise with documents, in standardising electronic access to our doors, and by recognising the allies we have in family historians.” (Tucker, p155) Family historians reliant on online resources need archives to be willing and able to utilise social media in order to share information about their collections.

Theimer (2010) and Nogueira (2010) describe the benefits and challenges of social media for archives, exploring how organisations can use these cheap resources to experiment and develop new services. Archivists using social media to share professional knowledge prompt others to use these tools through websites such as "The Interactive Archivist" which provide case studies to highlight different ways these tools can be used. However, there is still a lack of critical analysis of their use.

Archives in general have been slow to experiment and adopt features of social media as there is a wariness to move away from the traditional relationship between archivist and researcher and a desire to maintain authoritative metadata about digital collections (Yakel, 2007).

However archival web sites that are experimenting with social media were identified as "reimaging the ways in which researchers can interact with the archival record and with fellow travellers in the virtual archives.” (p163) As more archives begin to embrace these new tools there is a crucial need for the profession to undertake research to determine whether patrons find these tools useful (Samouelian, 2009).

Archivists are beginning to research and comment on these new approaches. Huvila (2008) studied two digital archives and formulated a new approach to archives, the participatory archive, which engages users in archival tasks utilising tools such as blogs, podcasts, tagging, and social communities. She noted the importance of harnessing knowledgeable users of archival collections "to contribute in the form of new and improved descriptions, translations, summaries, and relationships to other records” (p32). Palmer (2009) discusses a much needed change in mindset with archives and archivists needing to treat users "as peer collaborators, intrinsic to the process of meaning-making, rather than outside interlopers who must be kept at arm's length from the authoritative record.” (p3). A question remained, how will archives cultivate a 'deeper involvement' with users? 
An investigation undertaken by Krause and Yakel (2007) provides the only evaluation of user generated content in an archive. The Polar Bear Expedition Digital Collections remained intact while users were involved in the use of social navigation through commenting, collaborative filtering, and bookmarking thereby transforming the user experience in online archives. One reason for its success was the existence of an established audience engaged with the materials as they were already actively commenting on records. The researchers found that user generated content may increase the accessibility of archival materials and enrich traditional finding aids.

In conclusion, archives are using social media to share archival records and information online but with limited use of user-generated content due to a wariness to move away from traditional roles and a desire to retain control of metadata. The literature has examples of archives collaborating successfully with users yet there is a lack of knowledge of how archives are using social media to develop meaningful connections and conversations with users, specifically family historians. This paper will investigate how New Zealand archives are using social media to develop connections with family historians.

\section{Definition of Terms}

The key terms used in this study are archives and social media, and accordingly definitions are provided below:

Archives - "an organisation (or part of an organisation) responsible for appraising, acquiring, preserving and making available archival material.” (Archives New Zealand, 2006)

Social media - a relatively new term that is difficult to define as it incorporates many different tools. "Social media can take many different forms, including social networks, blogs, vlogs, social bookmarks, user reviews, video sharing, podcasts, rating systems, collaborative ranking, wikis, comments, message boards, and online forums. Technologies include: picture-sharing, wall-postings, e-mail, instant messaging, music-sharing, crowd-sourcing, and VoIP, to name a few. Primarily, social media depends on interactions between people as the discussion and integration of words builds sharedmeaning, using technology as a conduit.” NetLingo Online Dictionary, (2010). 
Family historian - "one who traces the descent of persons, or who is interested in the study of genealogies” (Oxford English Dictionary, 1989)

Family historians research information about individuals on their family tree and develop personal stories within a historical context.

\section{Research Questions}

This research project investigates how archives are using social media to develop connections with family historians. The intention is to improve online services for users of archives in the future. Research questions are:

- what types of social media are being used by archives?

- how are these social media tools being used?

- how are social media tools being used to interact with family historians?

Rutherford (2008) explored case studies of individual uses of social media written by librarians commenting that intention of these articles was to get others to experiment with their use e.g. blogs, RSS feeds, wikis. She went on to add that there was insufficient exploration of the benefits and costs of social media. Rutherford has now provided public libraries with much needed data concerning implementation issues; however there is limited detail analysis of their application by archives.

Rutherford (2008) used Rogers' Diffusion of Innovation theory as a framework for her study on “early adopter” libraries. Rogers' (1983) theory expounds a social and communication process where new ideas and practices are spread among members of a social system. It is appropriate to build on this research by continuing with this model.

In this study a small number of "early adopter" archives have been identified as innovative users of social media. They are utilising these tools to share resources and information, and to communicate with users. Family historians are identified as a diverse user group who provide focus and direction in the use of social media to develop meaningful connections with archives. Being a small study means the researcher cannot generalise the findings.

\section{Methodology}

This research project fits within the Interpretivist framework and uses qualitative methodology, an approach developed to analyse social phenomena. Interpretivist research 
deals with investigations in natural settings, offering the researcher a way to interact with subjects in an empathetic way allowing understanding and knowledge to develop from the data. The intent is to explore archives use of social media and acquire a deeper understanding of these services during the process.

\section{Ethical Approval}

The project received the approval of Victoria University of Wellington's School of Information Management Human Ethics Committee before it proceeded.

Before the research began informed consent was obtained from all participants and they were provided with the following information: title and purpose of the research, data collection and handling, with confidentiality and voluntary involvement guaranteed.

The researcher followed these ethical principles throughout the study.

\section{Organisational Settings}

All participants from this study came from libraries holding archival materials and are referred to as archives for this research project. The archives ranged from large public organisations to an academic and theological library. The participants held positions from Service Delivery Manager, senior reference staff, digital services librarians and family history librarian.

\section{Participants}

Participants for the research were initially selected from the Community Archive with organisations using social media being identified as “early adopters” (Rogers, 1995, p37).

The Community Archive, formerly the National Register of Archives and Manuscripts, is a freely available database consisting of archival organisations from around New Zealand. Currently 357 organisations publish information about their collections and these can be searched by subject, place, people or contributor. Archives New Zealand support and administer this database.

The Community Archive was explored using the "By Contributor" list and those archives with websites were investigated to establish if they were using social media. A list of nine archives using social media was drawn up with emails and contact names noted. 
An initial introductory email was sent to each contact in the archive asking them to become involved in the study. All archives replied with six respondents willing to participate in this study. An email with an attached information sheet, consent form and interview questions were then sent to each contact individual with anonymity the assurance of confidentiality for the duration of the study.

An interview time that suited each participant was organised with the consent form being signed and returned before each interview. Five respondents agreed to be interviewed by phone with one respondent agreeing to use instant messaging. Each interview lasted 40-50 minutes and was based on the questions emailed to each participant. All interviewees were thanked for their contributions and were sent a copy of the research project when it was completed.

\section{Data Collection}

Data for this study were collected in the form of phone interviews using Skype, which provided a low cost option to make phone calls within New Zealand. A piece of Skype software called Pamela Call Recorder was utilised to record the audio and these were later transcribed by the author.

Preliminary questions were emailed to all participants and these were followed with a personal interview to collect the data. Open-ended questions were used throughout the interviews to encourage more detailed responses. Similar questions were utilised with each participant to ensure the same general areas of information were collected. However, flexibility with questions was maintained so the researcher could remain open and adaptable to each interviewee and collect rich data in a relatively short time.

\section{Interview Questions}

The data collection consisted of answers to questions about archives' use of social media. The questions were concerned with finding out what types of social media are being used, how social media is being used to develop connections with family historians and what types of stories are being told through its use. A list of questions was sent to each interviewee with a proviso that further questions may be asked to explore particular topics in depth. The guided interview allowed this researcher to have a checklist of prepared questions "to make sure all the relevant areas are covered" yet provided freedom "to explore, probe and ask a question not previously specified” (Pickard, p176) when something was of interest. The 
purposeful conversations allowed participants to share their thoughts and stories about the use of social media within their organisations.

\section{Data Analysis}

Qualitative analysis was utilised for this research and was an ongoing process, taking place throughout the data collection process. This novice researcher took into account emerging themes during the interview process and refined the interview schedule when issues arose not previously considered.

Content analysis was chosen as the method of analysing data from the interviews. The transcripts were closely examined, passages highlighted and examined for similarities and differences. This approach allowed information to be broken down thereby letting themes and interesting concepts emerge from the data.

Comparative analysis was utilised to allow the researcher to move backwards and forward between transcripts, notes, and the research literature. The author could then bring coherence to the raw data and draw conclusions as to how social media was being used in archives. Comments from interviewees were identified to further illustrate the analysis.

Delimitations and limitations of the study: there is a deliberate limit to the size of sample, due to time constraints. The scope was limited to six New Zealand archives currently using social media tools.

\section{Results and Analysis}

This section examines social media used by the six interviewees in this study detailing what and how these tools are being utilised. This is followed by issues and concerns of social media use raised by participants during the interviews. There is analysis of the types of connections being made with family historians and finally there are three examples of social media tools being used to interact with these users.

\section{Social Media used by Archives}

"I saw it as a way of communicating with people on a different platform. Not everybody comes to the website for their information. They needed another way to become aware of events and things happening ... I use Facebook a lot to not only inform people but also to push people to our website, similar sort of lines for Twitter.” 
All participants in this study use a variety of social media for differing purposes. The main forms of social media utilised by these archives were blogs, wiki, Kete, Twitter, Facebook, Flickr, RSS feeds, YouTube and Delicious.

Five respondents were using social media in different combinations; three used blogs, Facebook and Twitter; one used a blog, Facebook, Twitter and Delicious; one used Kete, Twitter and RSS feeds. One respondent used a wiki only.

Archives utilised these combinations of social media to suit different functions. Five respondents commented that blogs brought depth to their content and provided them with a chance to promote their archival collections. Facebook was used to promote the archive's blog entries, services, events, and activities.

"I use it to promote the blog posts; we advertise exhibitions, anything topical that is happening in town, historic buildings lost, before and after photos. So I keep it short and sweet and often try and keep it quite regular whereas the blog ones are complicated posts and more informative."

Twitter brought services together as well as providing the ability to retweet or repost messages thereby allowing extra content to be added to the service. Delicious was used by one archive to bookmark pages of importance with Flickr and YouTube briefly mentioned by two archives to share images and video.

The Kete / wiki software were utilised as collaborative social media sites to upload historical and contemporary articles, images, video, audio, and web links providing local information for communities and historians. These tools provided archives with new ways to interact with users, involve local community members, whilst providing detailed local content. The two participants involved recognised time and effort was needed to develop community relationships so that the sites could indeed remain a shared partnership between the archive and community. Even though they were now mainly just administering the sites they noted that new content was necessary to keep users interested and returning to these sites.

\section{Archives Use of Social Media Tools}

"I put different things up on Twitter than I do on Facebook, like whenever I write a blog entry, that goes on Twitter and Facebook. On Twitter last year I spent time building a following amongst archives online.” 
Social media tools were seen as being relatively low cost and accessible to use so all participants were keen to experiment with their use. The majority of interviewees had used these tools personally and so moving to professional use had been just another stage. There was a general attitude of "let's do it" with a desire to communicate with the community using different platforms. One participant commented that not everyone comes to their website and so saw the potential of social media to promote their materials.

Archives were using social media to create interest in and share a deeper knowledge of their collections. They wanted to promote collection information in a more personalised way and social media was seen as the means to achieve this. They wanted to make collections accessible to users and social media assisted these connections. The majority of participants were enthusiastic about its use and acknowledged that they used social media to push out information and content about the collection. Social media was viewed as a novel way to reach out to users. It provided opportunities to meet users where they chose, be it Facebook, Twitter or a blog. These choices provide archives with the chance to "bang the drum" creating as much coverage or their resources as possible.

Two participants discussed how they used social media to build community history sites and create interaction through kete software. This tool was seen as a new way to build connections and develop participation within the community. The software provides a platform to build community sites as it allowed individuals to upload stories, photos, and personal archives. Content from the organisation's archives means cultural and heritage materials can be added as well.

Both of these participants commented that getting new material onto the sites was an ongoing issue and required more time and effort than they had been funded for. Extra funding had been secured by one participant who described how his organisation had formed a close partnership with community members and was now going to use this to create new content. The community had appreciated the items that had been uploaded to the site and were now keen to see more personal archives and stories available for others to access.

One participant noted that social media was part of a wider marketing strategy and needed to be kept in perspective. She was also keen to share archival information through publications, exhibitions, conferences, presentations and tours yet recognised social media as a way to get information about collections to the online community.

Three participants commented they use social media to keep in contact with other professionals in New Zealand and overseas. Social media tools were utilised to follow other 
organisations, interact with fellow archivists or librarians, and remain inspired by what others are doing.

A summary of the themes that emerged from the interviews is as follows:

- Social media tools are relatively low cost and accessible so archives are experimenting with their use.

- Social media is used to push out information, and is now another form of outreach to promote events, news, activities.

- Social media is used to share content about collections with the online community - to give life to the collection, to personalise collections, to tell stories about the collection.

- Social media allows archives to communicate, participate, and interact with users in their chosen online medium.

- Social media is used to collaborate with others to develop local history content.

- Social media is seen as part of a wider marketing strategy.

- Social media is used to connect and make contact with other professionals, nationally and internationally.

\section{Planning and Preparation}

"All we had to do was create an account and get something up there. That was easily within our IT skills but in saying that there are quirks about them both that can trip you up. There was nothing difficult in terms of the process ..."

Archives involved in this study had been using social media from six months to three years. Four interviewees had set up these tools with two continuing on with services already started. The planning process within this group differed; one participant involved the community in the setup process, two wrote a business case to use these tools, one created a scoping document with guidelines for staff, and one set up a page and waited to see what happened.

Participants mentioned the importance of attending conferences to stimulate interest with others just keen to try these new technologies. Even though all had management support from within their organisations none had any formal social media strategy and were now keen for further guidelines, support and direction from such a document. Three participants were going through transitions in their organisations and were looking at developing social media policy in the future. One participant commented that their organisation did not want a social 
media strategy at the start as it allowed them to be more creative and build the space themselves, however did acknowledge that guidelines helped to create structure for staff. Participants commented that social media tools were low cost, relatively easy to use and could be managed without great difficulty. They were keen to experiment with their use and used them both for personal and professional reasons. One participant shared how personal success with social media prompted its use for professional reasons. "I've had personal success with Facebook myself. As a family history librarian I have a deep personal interest in family history as well and I have managed to have previously unknown family members find me on Facebook.”

Another participant reflected on using social media for professional reasons yet thought it had unintended outcomes for users; "I use Twitter to connect with professionals in the field as well, internationally there is quite a large network of family historians and genealogists and we share information like resources, like have you seen this blog?, have you seen this database? etc. We do a lot of learning and sharing and it has the offshoot of informing our customers as well, because I have a quite a few general members of the public who also follow me on Twitter." This transparency provides a platform to provide information and knowledge about resources in an informal way whilst allowing users the opportunity to explore these in their own time.

Participants used social media daily, weekly, and monthly depending on the tool being used, with many discussing the importance of regular posts to sustain interest. Over half noted that traffic would drop off if new content was not added regularly.

Four participants commented that blog postings required the most time and energy as this was the platform to develop a deeper awareness of archival content. "You can talk for ever and a day about the fact that we have 10 kilometres of archives but people don't really understand what that means until someone takes one of the collections out and does what we have done on the blog."

The kete required the most resources during the initial setup phase. More staff were involved with planning, liaison, and the training of community volunteers who were to digitise and load content onto the site. Once past this initial setup phase minimal staff was then required to maintain and edit these sites. 


\section{Participation Levels}

"I would like to encourage people to interact with the page a bit more. I know that people are going there, I know that they are looking."

Social media tools are being seen as offering archives new ways to engage and connect with online users. All participants noted limited levels of participation from users visiting their social media pages. If users were keen on a topic then they would frequently add comments and share information with the favourite subjects being personal histories, food, places, and objects. Users contributed likes and affirmations but with limited comments being made. All participants commented they would like to see more responses and that even if users did not choose to comment there was still a good deal of interest in the pages and this encouraged them to remain motivated. The majority noticed that traffic was slowly increasing to their pages. There was universal agreement that regular postings were important to build a following and to keep users revisiting and interacting with their content.

Limited comments did not concern the majority of participants as they recognised it took time to develop a profile. "It takes time to build a following; it takes time to build momentum and interest. It takes a long time. You need content; interesting things to say otherwise you are a "me too" voice or a hollow person that doesn't have a voice on the internet. What you are saying needs to be useful, and ideally you need to and I haven't been very good at this, you need to engage with people online, you are supposed to have conversations with them and that is really hard to do. I find it really hard to do."

During the interviews participants discussed ways to build a social media profile:

- $\quad$ target the community - e.g. use a photo hunt to get content, upload family history photos and ask questions

- involve the community / build relationships during the start-up / project group, collaborate with others

- involve customers in learning new skills and adding content - targeting older people who lack skills and technology, yet have content information

- track statistics - check for increasing traffic

- find customer niches - put contexts on pages that interest people

- develop community history - approach individuals, organisations and retailers for social history information 
All wanted to encourage greater interaction with their communities yet did not expect too much at present. They saw themselves as experimenting with social media but did think they could be doing more with these services.

One participant commented that users editing others' work had not developed as expected and this was also reflected in other social media used by archives; "That feature has not kind of taken off and there tends to be a reluctance to edit people's work, particularly if they don't know that person. What tends to happen is that someone puts something in and it might get a comment instead of utilising the wiki tool." It was acknowledged that it could be hard for others to add comments to family stories as they are personal and that people may not want to share everything straight away. He went on to wonder if this really mattered and commented that attracting different users might create new interactions.

As comments to pages were low the majority of participants did not need to moderate responses made by users. However one participant did note that their organisation's moderation of user comments had led to fewer responses being contributed to the page. Users were not keen to have their comments moderated and this had impacted on the site with less use and fewer contributions.

Half the participants commented that the lack of technological skills by older users could be hindering participation with social media. Family historians were seen as older users and as such lacking the technological skills to use these tools. However, one participant challenged this perception as she noticed a large number of older people using Facebook to connect with family members. Her comment reveals why family historians are using social media to connect with others; "One of the things about being interested in family and genealogy is that you are not just interested in the dead; you are interested in the living as well, so you want to find people who are connected to you. Also these new family members you meet might have further information about ancestors you don't know about. It's a two way thing." This insight reveals why family historians are using social media and recognises the online connections and collaborations that can occur quite naturally for users.

One participant noted that with technological support and training older users do provide content and comments to pages and provided an example of an elderly customer adding hundreds of historical photos to their site. There is a perception amongst archivists that family historians, as older users, lack technological skills yet many family history societies and organisations are now active on social media. Family historians want to connect with 
other researchers and regularly use message boards, mailing lists and surname listings so a move to social media is another opportunity to make connections and continue with research.

One reflective participant wondered whether their blog didn't really encourage interaction and thought they could do more, commenting that it was time to assess what they were doing. This issue was discussed by others with the majority using tracking statistics to assess and monitor their sites. They would look at and review the number of visits to the site, what people were looking at, and what is successful. This provided direction and focus to further postings.

\section{Issues with Social Media}

"I am trying to encourage more participation from other members in the team. I would like to see them writing for it a bit more because I have quite a lot to do."

During the interviews participants discussed concerns and tensions that arose when using social media. They only discussed individual issues briefly within the context of the interviews so further research needs to be undertaken to understand how significant these are. All wanted to do more with social media but felt constrained by the following:

- Participants were often reliant on others to provide content and this made regular postings difficult, so were concerned about retaining followers and building a following.

- Writing was a time consuming process which required more effort than they had realised.

- Social media required energy and enthusiasm; they had other work to complete and would like more time to work on postings.

- There were conflicting pulls and pressures from within the organisation. There was a perceived need to "get going” with social media and yet concern that social media could damage the archival responsibilities of the organisation.

- Limited resources - this was an ongoing issue for all respondents as social media was often not resourced from within the organisation and was seen as an add-on.

- Lack of commitment, funding and direction from within the larger organisation which lead to frustration at times. 


\section{Social Media used to interact with Family Historians}

"With Twitter I am on there daily and I tweet about not only our department but also what is happening out in the family history community ..."

Examples of using social media tools to specifically interact with family historians were found to be limited within this study. Four of the six interviewees commented that they did not have any specific contact with family historians. Many viewed them as being a group of older adults who were generally not using social media and were hindered in its use because of a lack of technological knowledge. The following comment reflects a general assumption; "People who are doing research in their fifties and upwards are retired and social media is not their kind of thing." These participants viewed themselves as using social media to facilitate interaction with the wider community, other researchers and professionals but not really family historians.

One interviewee's comments did challenge this viewpoint. As an older adult and family historian herself she readily uses social media to make contact with known and unknown family members as well as connecting with online genealogical communities. As she has found these services personally rewarding this then became the motivation to use social media professionally. She keeps her personal and professional profiles separate and is keen to investigate further uses of social media. She has found professional relationships made using Twitter have benefited her professionally with opportunities to become involved in family history events and presentations. She commented that older people are now on Facebook and social media is now being used by many family history societies.

Another interviewee noted that whilst older users did indeed lack web skills and were not familiar with software he did comment that with time and resources volunteers could be taught to learn these skills. Once these skills were learned the volunteers provided much appreciated family historical content for the kete. He discussed the commitment needed by the organisation to engage and encourage this section of the community so they would continue to remain involved in developing the kete for researchers and family historians in the future.

The interviews undertaken for this research provided interesting examples of how archives are using social media to interact with users and are worth sharing. The examples below come from different organisations and are structured according to the software tool. The 
intention in sharing these is to encourage others to build on the ways social media is being used and to discover how it could be used to develop connections with family historians.

\section{Kete}

Kete is open source software which can provide archives with an opportunity to collaborate with communities to create and share content online. It allows documents, video, web links, audio and images to be uploaded, linking them if needed to topics. The following example illustrates a unique collaboration which aims to preserve New Zealand's Chinese heritage for future generations and provide a useful tool for family historians.

Family history was identified as foundational to building this site and early on involved training volunteers, usually older Chinese adults, to digitise photographs and write their stories. At present there are two hundred and thirty topics with seventy-seven digitised documents allowing users a rare glimpse into life in the Chinese community. "We were pleased when setting up the content when M. C. had put some wonderful stories about herself and they were added to in time with things about her family. They are good family stories, and cover the experience of a Chinese living in New Zealand. They are not long but they are really interesting and that is the type of content we want to encourage people to do."

With interest from the community they began to provide more genealogical information. The community were keen to get pictures of cemetery stones, with transcriptions of the stones, and to have these photographed and uploaded to the site. This allowed users to view and share the information from anywhere in the world.

The kete began to develop social history on the site by digitising photos around critical features of importance to the community such as food and sport. For example images of roast pig pits which were constructed by gold miners and market gardeners in the 1880s and 1890s, with a few still being used, were included. Every year at Easter Chinese from all over New Zealand gather together and have a sports tournament named the "TenTen Tournament”. A number of journals, photographs and video from 1949 through to the sixties have been digitised and are now available for everyone to look at. "We digitised their Ten-Ten celebrations which are their sport tournament journals. We digitised about eight to ten and they were pleased to see those as it made them available for everybody. They are all keyword searchable; you can look for people and find your friends, find yourself and see the photographs." 
The site has a bilingual interface and translating feature allowing content to be translated from English to Chinese and Chinese to English. This invaluable service provides familiarity and flexibility for its users. The kete now has over one hundred and seventy discussion threads, with information on deaths, family trees, links to Papers Past, discussions on food, New Year and more. Individuals are participating and sharing content enabling this site to become a useful tool. Not only does this resource provide family historians with records that enrich knowledge of their ancestor's lives it presents a rare window for the wider community.

\section{Twitter}

Twitter is where you can make short posts of 140 characters or less to give links to photos, websites, blog posts, or just ask questions and hold conversations. Twitter posts, or tweets, are searchable so you can find people interested in the same things as you and learn from people who share your interests.

The following example illustrates how a national organisation can use Twitter to share digitised versions of collection objects. This organisation has been using Twitter since 2008 and at present has nearly four thousand followers who receive daily postings about items. They have provided over eighteen hundred tweets to their followers. Other forms of social media are used but Twitter has been the most successful because it is instantaneous, allows online conversations and is a proactive customer service.

Twitter is tied to one simple task and is seen as a way to increase awareness of the collection whilst at the same time enabling community participation. The material for the post comes mainly from images in the pictorial collection and excerpts from historical newspapers, often quirky items chosen to elicit the most interest. There is no concern about copyright as the images from the collection do not need clearance.

Each day a tweet is comprised of one image from the collection, something is said about it, and is then posted at morning and afternoon tea when people are checking their feeds. Often people respond to the initial tweet and continue the joke or respond in different ways and carry the story forward. "I think the thing that worked well with Twitter is that it was tied to one simple task - expose one image from our collections, say something funny about it, and post at morning/afternoon tea time when people will be checking their feeds." 
Digitised historical newspapers aid genealogists as they contain birth, deaths, obituaries, articles, and advertisements; they are searchable using keywords, and they provide a window into an ancestor's past. The minimal information supplied in a tweet may not be helpful for people actively researching their family but it does provide users with opportunities to find like-minded people, locate other organisations that could aid free research through the "we follow" tab, link to the historical paper, and it allows sharing by retweeting. The immediacy of Twitter provides opportunities for organisations and users to communicate and share information in real time thus creating a conversation within an online environment.

\section{Facebook}

Facebook is a social networking site used by 500 million people around the world to connect with friends and family. This application facilitates sharing and publishing of a user's information with news posted on the user's “wall”. Users can create profiles with photos, lists of personal interests, contact information, and other personal information. Facebook users check other's "walls" to stay up-to-date with friends and this simplifies the process of remaining in touch.

During this research Facebook was typically utilised by participants to reach out to customers by creating pages displaying information about events, presentations, archival records, additions to the collection, links to other websites, databases, blogs, and also to upload photos. Once a user "likes” an organisation's page then status updates appear on the page making it easy for the archive to share information.

The following story provides an example of how Facebook was utilised to undertake a family history reference enquiry and illustrates how this service can engage users in a deeper level of participation. Usually within this organisation research enquiries were processed through the website contact form or by phone, but in this instance the customer, who already used Facebook, made the initial contact. The interviewee decided to encourage this contact as she was keen to develop the service.

The customer had already used a database on the website to locate tombstone information and photographs. She was trying to find information concerning the death of her greatgrandmother. She had found information relating to her great-grandfather and the mention of his wife but no mention of when this person died. She posted an entry on Facebook 
explaining what she had found in the database and that she now required photos of her greatgrandfather's tombstone and information about his wife.

The interviewee looked through the death notices and was able to provide copies of these to the customer. She also went to the archive's photograph files and got copies of the tombstones off the files and provided these to the customer. "She felt quite comfortable in doing all this on Facebook rather than going to the website because that is where she lives her life, on Facebook. She is happy now as she knows when her great-grandmother died and she has a photographic record of her great-grandfather's tombstone."

Privacy, often an issue with Facebook, was maintained at times as the interviewee could direct message the customer, yet she did try to keep the process as open as possible as she wanted to encourage other users to make use of Facebook in this way. This instance demonstrates that Facebook can be used to share and exchange information at a deeper level and be a helpful tool for genealogical collaboration.

\section{Conclusion}

This study was designed to provide archives with research on how social media is being used to develop connections with users and family historians in particular. It is a small study and although this does limit the ability to make claims about social media use, the interviews undertaken can inform archives as to what tools are being used and how they are being applied.

What types of social media are being used by archives? The main types of social media used were blogs, kete, Facebook and Twitter. Some tools were utilised to share and personalise collection content, developing knowledge and awareness of the archive in the process, e.g. blogs and kete. Other tools were used to push out information to online users and/or followers about the archive's events, activities, and collection thus creating greater awareness of the archive, e.g. Facebook and Twitter.

How are these social media tools being used? Archives are using social media in various combinations to serve different purposes. With relatively low cost and ease of use participants in this study were able to utilise social media tools to communicate, to participate, and to interact with online communities. Admittedly there were limited levels of interaction and participation but this could be due to the relative newness of these services and correspondingly that participants were still experimenting with its use. All interviewees 
were keen to engage more effectively with users yet recognised that it would take time to build a following.

In the majority of cases social media tools were used to achieve maximum access to the wider community, allowing archives to meet users within their chosen medium. In 2008 Huliva commented that social media could be used to make an archive more transparent, to orient them towards users, and to contextualise documents. Interviews undertaken during this study confirm these comments.

How are social media tools being used to interact with family historians? Family historians were chosen as a user group for this study as they actively use archival records to research their “personal history”. During the study there were limited examples of archives connecting with family historians. The majority of participants shared anecdotes to demonstrate how they were using social media tools to interact with users. These ranged from users using the "like" tab on Facebook, retweeting posts on Twitter, sharing family stories on Kete, through to comments on blogs. Three participants shared detailed stories of social media tools being utilised by archives, illustrating how they are interacting with family historians at this time. All interviewees sought greater levels of participation and were now keen to reassess how they were utilising these tools.

Half the participants viewed family historians as being older adults who do not use social media and lack the technological skills. This view was challenged by only one participant hence the inference remains that family historians do not use social media (there is a very active family history social media networking site hosted by TradeMe. It is likely the family historians on the TradeMe genealogy group would dispute this perception).

There may be other reasons that archives have limited connections with family historians. Huliva described social media tools as limiting “participation to a conversation about a record instead of using a record and its description as a conversation and an arena for participation” (p. 27). In this study, social media is predominantly used as an outreach tool to share collection information, events, photos etc with the community. It is possible that pushing out information in this way may hamper the connections and conversations archives could develop with users. If that is the case then social media may need to be utilised in different ways to develop greater participation with family historians. As yet New Zealand archives are still to experiment "using” the archival record to communicate with users. 
Archivists and family historians have much in common. Both groups seek to make meaning from the records they use and make connections with the past and present during this process. The common ground between these two groups may provide the impetus for archives to push the boundaries when utilising social media tools in the future.

The adoption of new technologies involves the management of risk and uncertainty. According to Rogers’ Theory of Diffusion (1995) “early adopters” help spread the word about new technologies and can therefore minimise such risk. The six interviewees in this study readily shared their insights about their uses of social media. Participants revealed how they were "beating the drum" and taking the chance to open their doors wider by harnessing these relatively low cost easy to use tools. Social media is providing archives with novel ways to interact and communicate with their online communities. These "early adopters" have provided archives with valuable feedback about social media tools minimising the risk for others in the process.

They have been discovering that these tools enable their services to achieve greater levels of interactive engagement with users and although confident that the use of social media tools will increase over time, they are keen to realise a wider acknowledgement in their respective workplaces that these tools do help to foster participation, collaboration and conversation with the wider community. 


\section{Further Research}

- Undertake a larger study to provide more data about the use of social media in archives, record any changes in its use.

- Include information from social media pages in the research to add depth to the material gathered.

- Research the implications of archives' use of social media in greater detail.

- Study family historians' use of social media in relation to their use of archival records / materials.

- Research organisations using archival records, user generated content and social media. 


\section{Acknowledgements}

I would like to thank my supervisor Gillian Oliver for her help, guidance, and support whilst undertaking this research.

I would like to acknowledge and thank the participants for their co-operation, willingness, and openness provided for the duration of this study. They readily shared their time and thoughts. Without their goodwill this research could not have been completed.

I would also like to thank my family and friends who encouraged me to complete this research during a difficult time in Christchurch 2010 / 2011. 


\section{Appendices}

- Information sheet

- Consent form

- Interview schedule 


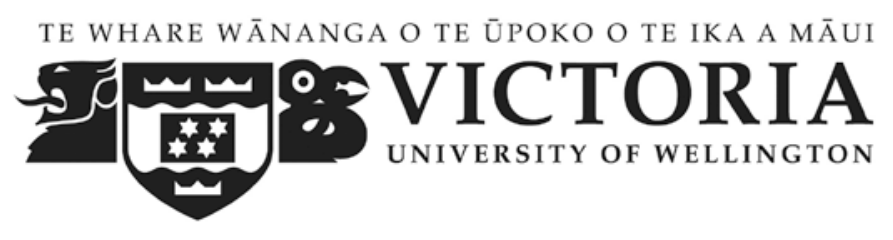

INFORMATION SHEET

Archives use of social media to develop connections with family historians

Researcher: Julie Paterson

School of Information Studies, Victoria University of Wellington

I am a Masters student in Info 580 at Victoria University of Wellington. As part of this degree I am undertaking a research project leading to a research report. The project I am undertaking is investigating archives use of social media to develop connections with family historians. Approval for this research project has been granted by the Human Ethics Committee from the Victoria University of Wellington.

The study will investigate how archives are using social media to develop connections with family historians. The intention is to improve online services for users of archives in the future. Research questions will focus on:

- what social media is being used?

- how is social media being used?

- how is it used to make connections with family historians?

- what stories are told through the use of social media?

I am inviting archivists using social media tools to participate in this study. Participants will be asked to complete a Skype interview, utilising instant messaging or audio, at a time convenient to the interviewee. The scheduled interview will be approximately 40 minutes with a transcript or tape of the interview recorded during this time. Questions will be emailed a week prior to the interview to allow time to consider responses before the interview takes place.

Should any participant feel the need to withdraw from the project, they may do so without question at any time before the data is analysed by 20/12/2010. In event of withdrawal any information provided a participant will be deleted and not used in this research. Responses collected will form the basis of my research project and will be put into a written report on an anonymous basis. It will not be possible for you to be identified personally.

All material collected will be kept confidential. No other person besides me and my supervisor, $\mathrm{Dr}$ Gillian Oliver, will see the transcripts of the interviews. The thesis will be submitted for marking to the School of Information Studies and deposited in the University Library. The transcripts will be destroyed two years after the end of the project.

If you have any questions or would like to receive further information about the project, please contact me at my email address: patersjuli1@myvuw.ac.nz or by phone: 03-3849177. You may contact my supervisor, Dr Gillian Oliver, at the School of Information Studies at Victoria University, P O Box 600, Wellington, phone: 044637437 or email: gillian.oliver@vuw.ac.nz 


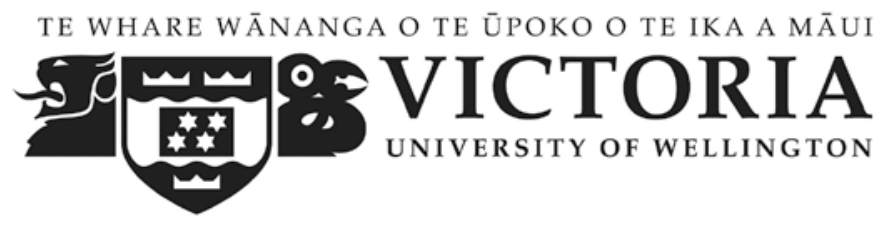

\section{CONSENT FORM \\ VICTORIA UNIVERSITY OF WELLINGTON \\ CONSENT TO PARTICIPATION IN RESEARCH}

\section{Archives use of social media to develop connections with family historians}

I have been provided with adequate information relating to the nature and objectives of this research project. I have understood that information and have been given the opportunity to seek further clarification or explanations.

I understand that I may withdraw myself (or any information I have provided) from this project (before data collection and analysis is complete) without having to give reasons or without penalty of any sort.

I understand that any information I provide will be kept confidential to the researcher and the supervisor, the published results will not use my name, and that no opinions will be attributed to me in any way that will identify me. I understand that transcript of the interviews will be electronically wiped at the end of two years.

- I consent / decline to being recorded during the interview about archives and social media use.

- I understand that I will have an opportunity to check the transcripts of the interview before publication.

- I understand that the data I provide could be used for publication in a research journal or used at a professional conference.

- I can request a summary of the results of this research when it is completed.

- I agree to take part in this research

Signed:

Name of participant

Date 


\section{Interview schedule}

Archives use of social media to develop connections with family historians.

The following questions are indicative of the type of question that will be asked during the interview. Further questions may be asked in order to explore particular topics in depth.

As an archive what type /s of social media are you using?

How long for? Who is involved?

What planning / preparation occurred before its implementation?

What social media strategy does your archive have? e.g. on moderation of comments

How are you using social media? Are there links to content? If so what?

Who comments / participates, how?

What sort of participation is occurring with these tools?

How do you assess and evaluate the use of your social media tools?

How are social media tools being used to interact with family historians?

Do you have any further comments about the use of social media by archives? 


\section{Bibliography}

Archives New Zealand (2006). Glossary of Archives and Recordkeeping Terms. Retrieved 24 April, 2010, from http://continuum.archives.govt.nz/files/file/guides/g5/g5-glossary.html

Barratt, N. (2009). From memory to digital record: Personal heritage and archive use in the twenty-first century. Records Management Journal. 19 (1), 8-15. Retrieved from Emerald database.

Casey, M.E. \& Savastinuk, L.C. (2007). Library 2.0: A Guide to Participatory Library Service. U.S.A.: Information Today, Inc.

Daines, J.G. \& Nimer, C.L. (2009). The Interactive Archivist. Retrieved 23rd Aug, 2010 from http://lib.byu.edu/sites/interactivearchivist/case-studies/

Darnell, L. (2008). Finding aids. In J. Bettington (Ed.), Keeping Archives. (pp 379-401). Australian Society of Archivists Inc, Dickson: A.C.T.

Dorner, D.G. Liew, C.L. Yeo, Y.P. (2007). A textured sculpture: The information needs of users of digitised New Zealand cultural heritage resources. Online Information Review. 31 (2). 166-184. Retrieved from Emerald database.

Facebook. (2011). Retrieved 20 April, 2011, from http://www.facebook.com

Farkas, M. (2007) Social software in libraries: building collaboration, communication and community Online. Medford, N.J: Information Today.

Fichter, D., \& al. (2008). Social Media Metrics: Making the Case for Making the Effort. Online. 32(6), 54-57. Retrieved from Library Literature Fulltext database

Gorman, G.E. \& Clayton, P. (2005). Qualitative Research for the Information Professional A Practical Handbook. London: Facet Publishing.

Holley, R. (2010). Tagging Full Text Searchable Articles: An Overview of Social Tagging Activity in Historic Australian Newspapers August 2008 - August 2009. D-Lib Magazine. 16(1/2). Retrieved from http://www.dlib.org/dlib/january10/holley/01holley.html 
Huvila, I. (2008). Participatory archive: towards decentralised curation, radical user orientation, and broader contextualisation of records management. Archival Science. 8(1), 15-36. Retrieved from EBSCO database.

Kete. (2011). Retrieved 20 April, 2011, from http://kete.net.nz/

Krause, M.G.; Yakel, E. (2007). Interaction in Virtual Archives: The Polar Bear Expedition Digital Collections Next Generation Finding Aid. The American Archivist. 70(2), 282-314. Retrieved from LISA database.

Lankes, D.R.; Silverstein, J.; Nicholson, S. (2007) Participatory Networks: The Library As Conversation. Information Technology and Libraries. 26(4),17-33. Retrieved from LISA database.

McKemmish, S., Piggott, M., Reed, B. \& Upward, F. (Eds.). (2005). Archives:

Recordkeeping in society. Wagga Wagga: Centre for Information Studies.

Matthews, B.S. (2007). Online Social Networking. In N. Courtney (Ed.). Library 2.0 and Beyond (pp75-89). Westport, CT: Greenwood.

Neilson Company (2010) Social Media Report. Retrieved 25 January, 2011, from http://nz.nielsen.com/news/Social_Media_ReportJul10.shtml

NetLingo Online Dictionary (2010). Retrieved from VUW database http://www.netlingo.com/dictionary/s.php

Nogueira, M. (2010). Archives in Web 2.0: New Opportunities. Ariadne. 63, April. 1-11. Retrieved 29 Aug, 2010 from http://ariadne.ac.uk.

Oliver, G. (2010). Transcending silos, developing synergies: libraries and archives. Information Research. 15(4). Retrieved 17 April, 2011 from http://informationr.net/ir/154/colis716.html

Palmer, J. (2009). Archives 2.0: If We Build It, Will They Come? Ariadne. 60, July. 1-6. Retrieved from LISA database.

Pamela Recorder for Skype. (2010). Retrieved 6 November, 2010, from http://www.pamela.biz/en/ 
Pickard, A.J. (2007). Research Methods in Information. London: Facet Publishing. Rosenbusch, A. (2000). Are Our Users Being Served? : A Report on Online Archival Databases. Archives and Manuscripts. 29(1), 44-61. Retrieved from LISA database.

Rogers, E.V. (1995). Diffusion of Innovations. Retrieved from http://www.mauriceanemaat.nl/uni/Scriptie/ARTIKEL_ROGERS_DIFFUSIONINNOVATIONS.pdf Samouelian, M. (2009). Embracing Web 2.0: Archives and the Newest Generation of Web Applications. The American Archivist. 72(1), 42-71. Retrieved from LISA database Skype. (2010). Retrieved 6 November, 2010, from http://www.skype.com/intl/en-us/home Smith, D. (2010). Using Social Networking Tools to Promote Genealogy and Local History Collections and to Instruct Researchers in Their Use. World Library and Information Congress: 76th Ifla General Conference and Assembly. Retrieved from http://www.ifla.org/files/hq/papers/ifla76/73-smith-en.pdf

Sutherland, P. (2010). From library automation to Library 2.0: exploring Web 2.0 tools, while reflecting on traditional values as we move towards Library 2.0 and beyond. Paper presented at VALA 2010, Melbourne, Australia. Retrieved from http://christchurchcitylibraries.com/Bibliofile/Papers/

Theimer, K. (2010). Web 2.0 tools and strategies for archives and local history collections. Facet Publishing, London.

Tucker, S. (2006). Doors Opening Wider: Library and Archival Services to Family History. Archivaria 62, 1-32. Retrieved from Journal Finder VUW

Twitter. (2011). Retrieved 20 April, 2011, from http://twitter.com/

Yakel, E. (2004). Seeking information, seeking connections, seeking meaning: genealogists and family historians. Information Research. 10 (1). Oct 2004, No page numbers. Retrieved from LISA database.

Yakel, E. Shaw, S. \& Reynolds, P. (2007). Creating the next generation of archival finding aids. D-Lib Magazine 13 (May/June). In Info 534 [CDROM]. Wellington: Victoria University of Wellington 
Yakel, E. (2006). Inviting the user into the virtual archives. OCLC Systems and Services 22(3), 159-163. Retrieved from Emerald database. 
Word count: 8,174

Font: Times New Roman 